\title{
Marmara Bölgesinde Yeni Doğan Buzağı İshallerinde Bovine Coronavirusların Saptanması ve Patojenite Çalışması
}

\author{
Züleyha Pestil1', Veli Gülyaz ${ }^{1}$, Mustafa Hasöksüz² \\ ${ }^{1}$ Pendik Veteriner Kontrol Enstitüsü 34890, Istanbul \\ ${ }^{2}$ Viroloji Anabilim Dall, İstanbul Üniversitesi Veteriner Fakültesi Avcllar, İstanbul \\ Geliş Tarihi / Received: 08.12.2014, Kabul Tarihi / Accepted: 09.07.2015
}

\begin{abstract}
Özet: Bu çalışma Marmara Bölgesi'nde yeni doğan ishalli buzağılarda BCoV'unun yaygınlığının tespiti, virus izolasyonu ve aşı virusu belirlenmesi amacıyla gerçekleştirildi. İstanbul, Tekirdağ, Kırklareli, Kocaeli illerinden sırasıyla 28, 37 , 15 ve 20 adet olmak üzere toplam 100 adet ishal görülen $0-2$ aylık buzağıya ait gaita numunesi çalış1ldı. Her bir numune örneği BCoV antijen detection ELISA ve PCR ile test edildi. Yapılan analizler sonucu gaita numunelerinden PCR testi ile 2 adet $\mathrm{BCoV}$ nükleik asit varlığı saptand1. Pozitif bulunan gaita örnekleri 1/10 dilüsyonlarda sulandırılıp HRT hücre kültürüne ekimleri yapıldı. Pozitif numunelerden yapılan hücre kültürü ekimlerinde BCoV izole edilemedi.
\end{abstract}

Anahtar kelimeler: Coronavirus, Buzağı, ELISA, izolasyon, PCR, Patojenite

\section{The Determination and Pathogenicity of Bovine Coronavirus in Newborn Calves with Diarrhea in Marmara Region}

\begin{abstract}
The aim of this research project was to determine the prevalence of BCoV infection in dairy enterprises in Marmara region, Turkey and to isolate the seed strain for a Turkish vaccine. A total of 100 feces samples obtained from calves up to 2 months were examined that were collected 28, 37, 20 and 15 samples from provinces of İstanbul, Tekirdağ, Kocaeli and Kirklareli, respectively. All samples were tested for BCoV using by ELISA and PCR assays. Two samples were detected as positive by PCR. For virus isolation, 1/10 dilution of feces samples was inoculated in HRT cell cultures. On contrary to assays, the virus was not isolated.
\end{abstract}

Key words: Coronavirus, calves, ELISA, isolation, PCR, pathogenicity

\section{Giriş}

Bovine coronavirus (BCoV) ilk defa Mebus ve arkadaşları tarafından 1973 yılında neonatal buzağ 1 ishalleri etkeni olarak bildirilmiştir. Ayrıca virus sığır solunum sistemi ve ergin sığırların kış dizanterisi etkeni olarak tanımlanmıştır. Bir vakada buzağılarda deneysel çalışma esnasında kaza eseri insanlara bulaştığ 1 bildirilmiştir $[8,18]$.

$\mathrm{BCoV}$ etkeni tracheal ve lenfoid organ kültüründe üretilmekte birlikte cell line hücre kültürlerinden HRT-18, Vero, MDBK, MDCK hücre kültürlerinde de üretilmektedir. Hücre kültürlerine tripsin ve pankreatinin eklenmesi virusun üremesi üzerine olumlu etkisi vardır. Hücre kültürlerinin erken pasajlarında virus üremesine bağlı olarak tipik sitopatojenik (CPE) odaklar görülmeyebilir. İleri pasajlarda syncytia oluşumu, hücrelerin yüzeyden ayrılmas1 gibi oluşumlarla CPE odakları netleşir. Virusun üremesine bağlı olarak meydana gelen plaklar besiyerine agaroz ve tripsin eklenmesiyle net olarak gözlenir. Deneysel enfeksiyon amaciyla kolostrum almamış Germ-free ve konvansiyonel buzağılar kullanılır $[4,8]$.

BCoV partikülleri $80-160 \mathrm{~nm}$, ortalama 120 nm çapındadır. BCoV izolatları poliklonal serum ile yapılan çalışmalarda tek serotipe sahiptirler. Ayrıca monoklonal antikorlar ile N, S, HE proteinleri bak1mından farklı suşlar saptanmıştır. Ayrıca suşlar arasında CPE ve plak oluşturma özellikleri bakımından farklılıklar olduğu bildirilmiştir. Virus üremesine bağlı hücre stoplazmasında inklüzyon cisimcikleri saptanir [12].

BCoV'unun meydana getirdiği enteritis vakaları buzağıların yaşına, immun sistemin durumuna, virus suşuna ve dozuna bağlı olarak değişiklik gösterir. Özellikle kolostrum almamış genç buzağılarda şiddetli ishal ortaya çıkar. Deneysel enfeksiyonlarda virus inokulasyonunu takiben 48 saat sonra sarı ishal gelişir ve 3-6 gün sürer. Bu periyotta virus gaita da saptanabilir. Akut dönemde buzağglar anorek- 
sik ve durgundur. Eğer ishal şiddetliyse buzağılarda dehidrasyon ve pireksi görülür. Hastalık şiddetliyse buzağılarda ölüm oranı yükselir. BCoV ve BRV enfeksiyonları çoğunlukla genç hayvanlarda görülmektedir. Yeni doğanlar genellikle yaşamlarının ilk haftasında enfeksiyona duyarlı olup, BCoV enfeksiyonu sıklıkla 3-21 günlük yaş grubundaki buzağılarda kolon ve incebağırsaklarda meydana gelen lokal bir enfeksiyondur [21,22].

BRV enfeksiyonu ve $\mathrm{BCoV}$ ile gelişen sindirim sistemi enfeksiyonlarında etkenlerin alınması enfekte gaita ile bulaşık yem ve sular ile oral yoldan olmaktadır. Erişkin hayvanlar genellikle BRV ve $\mathrm{BCoV}$ ile subklinik enfekte olduklarından, hastalığın sürü içinde yayılmasında önemli rol oynarlar $[11,13]$. Virusun saçılış1 gebeliğin geç dönemlerinde özellikle doğum yaptıkları gün muhtemelen hormonal değişiklikler ve hormonların immun sistemdeki etkilerine bağlı olarak artmaktadır [2]. Bu nedenle sürü içindeki subklinik enfekte erişkin hayvanlar yeni doğan buzağıların etkeni edinmelerinde önemli rol oynarlar. Bundan başka sağlıklı görünümlü buzağıların nazal svap örnekleri ya da gaitalarından $\mathrm{BCoV}$, gaita örneklerinden BRV izolasyonları bildirilmiş olup, bu buzağıların virusu düşük titrede saçtıkları ve sürüde klinik enfeksiyonların oluşmasında önemli rol aldıkları bildirilmiştir [16].

$\mathrm{BCoV}$, İngiltere, Almanya ve diğer bazı avrupa ülkelerinde, Japonya ve Çin'de yeni doğan buzağılarda diyare etkeni olarak tanımlanmıştır [5].

Etken sığır popülasyonu arasında yaygındır. Virus hem ishalli hemde sağlıklı buzağılarda saptanabilir. Sığırlar arasındaki insidensi \%8-69 olurken, ishalli ve sağlıklı buzağılarda \%24'e kadar tespit edilmiştir. Yeni doğan buzağılarda ishallere neden olan en önemli viral etkenler arasında bovine rotavirus (BRV)'larla birlikte bovine coronavirus $[\mathrm{BCoV})$ 'lar önemli yer tutmaktadır. Ülkemizde ve diğer ülkelerde yapılan çalışmalar sonucu kimi ülkelerde $\mathrm{BCoV}$ enfeksiyonunun BRV enfeksiyonuna göre daha fazla olduğu, kimi ülkelerde ise tersi durum arz ettiği bildirilmektedir. Ülkemizde BRV ve $B C o V$ 'ların neden olduğu buzağ 1 ishalleri ile mücadelede başarılı olmanın bir yoluda etkenlerin varlığı ve oranlarının bilinmesine bağlıdır. Özellikle $\mathrm{BCoV}$ ishallerinin önlenmesi amaciyla gebe sığırlara yapılan aşılamaların etkinliği, hastalık etkeninin yaygınlığının bilinmesine bağlıdır[14].
Bu proje, Marmara Bölgesi'nde sığır yetiștiriciliği yapılan işletmelerdeki buzağılarda görülen $\mathrm{BCoV}$ izolasyonu, aşı suşu seçimi ve patojenitesinin saptanması amacıyla gerçekleştirildi.

\section{Materyal ve Metod}

\section{Materyal}

Gaita örnekleri: Bu çalışmada Marmara Bölgesi illerinden; İstanbul, Tekirdağ, Kirklareli ve Kocaeli'nde süt sı̆̆ırcıllı̆̆1 yapan işletmelerden sırasıyla $28,37,15$ ve 20 adet olmak üzere ishal görülen, 0-2 aylık toplam 100 buzağıya ait gaita numunesi işlendi.

Hücre kültürü: Virus izolasyonu ve serum nötralizasyon testleri için Human Rectal Tümör [HRT) hücre kültürü, ABD Ohio Tarımsal Araştırma ve Kalkınma Merkezinden temin edildi.

Referans Coronavirus suşu: $\mathrm{BCoV}$ Mebus suşu ABD Ohio Tarımsal Araştırma ve Kalkınma Merkezinden temin edildi ve pozitif kontrol olarak kullanildı.

Coronavirus hiperimmun serumu: $\mathrm{BCoV}$ Mebus suşu kullanılarak tavşanlarda hazırlandı $[5,9,13,19]$.

Vasat: Hücre kültürü ve virus üretimi amaciyla Glasgow Minimium Essential Medium (GMEM) kullanıld1.

Fötal Calf Serum: Hücre kültürü hazırlanmasında $\% 10$ oranında GMEM vasatına eklendi.

Pankreatin: $10 \mathrm{mikrogram} / \mathrm{ml}$ oranında virus üretme vasatına eklendi.

ELISA test kiti; Ticari ELISA test kiti (Bio-X Coronavirus Antijen Detektion Elisa Kit ) kullanıldi.

Deneme hayvanları: Çalışmada izole ve identifiye edilecek BCoV suşlarının buzağılarda patojenite çalışmaları amacıyla, BCoV aşısı yapılmamış ve doğum öncesi kanlarında $\mathrm{BCoV}$ karşı antikor taş1madıkları saptanan gebe sığırlardan doğan 4 buzağı kullanılacaktır [3]. İsolasyon gerçekleştirilemediği için deneme hayvanı kullanılmadı.

\section{Metod}

Gaita örneklerinin hazırlanması: İshalli buzağılardan toplanan 100 gaita örneği $10 \mu \mathrm{g} / \mathrm{ml}$ pankreatin, $100 \mathrm{IU} / \mathrm{ml}$ penicilin, $100 \mathrm{mg} / \mathrm{ml}$ streptomicin ve 
$10 \mu \mathrm{l} / \mathrm{ml}$ partricine içeren GMEM vasatı ile $\% 10$ oranında sulandırıldı. Sulandırılan gaita örnekleri 3000 rpm'de 30 dakika süreyle santrifüj edildi. Ayrılan süpernatantlar ve $0,22 \mu \mathrm{m}$ por çaplı membran filtrelerden süzüldü ve elde edilen süzüntüler cryoviallere taksim edilerek $-70^{\circ} \mathrm{C}$ 'de kullanılıncaya kadar muhafaza edildi $[8,13,17]$.

Coronavirusların RT-PCR ile saptanması: RNA izolasyonu: Gaita veya hücre kültürü örneklerinden RNA izolasyonu High Pure Viral Nucleic Asid Kit (Roche) protokolu uygulanarak yapıldı.

RT-PCR: RT-PCR aşaması [11]' nın bildirdiği yöntem kullanılarak One Step RT-PCR Kit (Q1agen) ile gerçekleştirildi.

İzole edilen RNA'lar BCoV'unun Mebus suşunun N proteininden seçilen $729 \mathrm{bp}$ lik (GenBank No. M16620) bölgeyi kodlayan spesifik primerler F:(-GCAATCCAGTAGTAGAGCGT-) ( 21-40); R:(-CTTAGTGGCATCCTTGCCAA-) (731-750); nested PCR için Fn primer, (-GCCGATCAGTCCGACCAATG-) (79-98);Rn primer, (-AGAATGTCAGCCGGGGTAG-) (467485) kullanıldı. RT- PCR ürünleri sırasıyla 730 ve 407 bp'dir.

\section{İlk tur PCR için;}

İzole edilen RNA'nın 2,5 $\mu$ l'si ile $0,3 \mu 1$ DMSO karıştırıldı ve üzerine $17,2 \mu 1$ master miks $(5,6 \mu 1$ DPEC'li su, $4 \mu 15 \mathrm{x}$ buffer, $4 \mu \mathrm{l}$ Q solusyonu, $0,8 \mu 1$ dNTP, $0,8 \mu 1$ enzim 0,5 'er $\mu$ primerler) eklendi. Karışımı içeren tüpler thermalcycler cihazına yerleştirilerek $50^{\circ} \mathrm{C}^{\prime} \mathrm{de} 30 \mathrm{dk}\left(1\right.$ siklus), $95^{\circ} \mathrm{C}$ ' de $15 \mathrm{dk}(-$ 1siklus), $95^{\circ} \mathrm{C}^{\prime} \mathrm{de} 1 \mathrm{dk}, 58^{\circ} \mathrm{C}^{\prime} \mathrm{de} 1 \mathrm{dk}, 72^{\circ} \mathrm{C}^{\prime} \mathrm{de} 2 \mathrm{dk}$ (30 siklus) ve $72^{\circ} \mathrm{C}^{\prime} \mathrm{de} 10 \mathrm{dk}(1$ siklus) olacak şekilde ilk tur PCR işlemi gerçekleştirildi.

İkinci tur nested PCR için; 2x MMix (Fermentas) $10 \mu \mathrm{l}$, DPEC'li su $6 \mu$, Primer Fn $1 \mu 1$ Primer Rn $1 \mu 1$ içeren karışım hazırlandı. Hazırlanan bu karışıma ilk tur PCR ürününden $2 \mu 1$ eklendi. Karışımı içeren tüpler thermalcycler cihazına yerleştirilerek(1 siklus) $95^{\circ} \mathrm{C}$ 'de $5 \mathrm{dk}, 30$ siklus için $95^{\circ} \mathrm{C}^{\prime} \mathrm{de} 1 \mathrm{dk}, 58^{\circ} \mathrm{C}^{\prime} \mathrm{de} 1 \mathrm{dk}, 72^{\circ} \mathrm{C}^{\prime} \mathrm{de} 2 \mathrm{dk}$ ve (1 siklus) $72^{\circ} \mathrm{C}^{\prime} \mathrm{de} 10 \mathrm{dk}$ olacak şekilde nested PCR işlemi gerçekleştirildi.

Birinci ve İkinci tur PCR ürünleri (cDNA) \%2'lik agarozda yürütülerek UV altında gözlemlendi [12].

Enzyme Linked Immunosorbent Assay (ELISA): Bu amaçla ticari ELISA test kiti (Bio-X Coronavirus
ELISA Kit) kullanıldı. Gaita örnekleri üretici firma tarafindan belirlenen uygulama yönergesi doğrultusunda işlenerek $450 \mathrm{~nm}$ filtre absorbansları okunmak suretiyle sonuçlar değerlendirildi $[2,7]$.

Human Rectal Tümör (HRT) hücre kültürü hazırlanması: Azot tankında muhafaza edilen HRT hücre kültürü $37^{\circ} \mathrm{C}$ 'lik benmaride hızlı bir şekilde çözdürüldü, 3-5X105/ml hücre olacak şekilde $\% 10$ FCS içeren GMEM vasatı ile sulandırılarak $25 \mathrm{~cm}^{2}$ 'lik flasklara $7,5 \mathrm{ml}$ konarak $37^{\circ} \mathrm{C}$ ' de ve $\% 5$ $\mathrm{CO}_{2}$ 'li ortamda monolayer hücre kültürü hazırlandı $[3,5,8]$.

Hücre kültüründe BCV izolasyonu: Gaita örneklerinden hazırlanan süpernatantlardan $100 \mu \mathrm{l} 25$ $\mathrm{cm}^{2}$ ' lik flasklarda üretilen HRT hücre kültürlerine ekimleri yapıldı. Bu amaçla, \%90 monolayer olarak üreyen HRT hücre kültürlerinin vasatları döküldü, $3 \mathrm{kez} 10 \mu \mathrm{g} / \mathrm{ml}$ pankreatin, $100 \mathrm{IU} / \mathrm{ml}$ penicilin, 100 $\mathrm{mg} / \mathrm{ml}$ streptomicin ve $10 \mu \mathrm{l} / \mathrm{ml}$ partricine içeren GMEM vasatı ile hücre yüzeyleri yıkandı ve $7,5 \mathrm{ml}$ pankreatinli GMEM vasatı konarak 1 saat süreyle $37^{\circ} \mathrm{C}$ 'de inkube edildi. İnkubasyon periyodu sonunda flasklardaki hücrelerin yüzeyleri $3 \mathrm{kez}$ pankreatinli GMEM vasatı ile yıkand 1 ve her flaska $10 \mu \mathrm{g} /$ $\mathrm{ml}$ pankreatin içeren 7,5 $\mathrm{ml}$ GMEM vasatı konarak $37^{\circ} \mathrm{C}$ 'de $\% 5 \mathrm{CO}_{2}$ 'li etüvde inkubasyona birakıld1. Her gaita örneğinden ekim yapılan 4 flask hücre kültüründen ikisine her iki günde bir $500 \mu \mathrm{g} / \mathrm{ml}$ saf pankreatin solüsyonundan 25 'er $\mu 1$ eklendi. Hücre kültürleri 10 gün süreyle her gün $\mathrm{CPE}$ oluşumları yönünden kontrolleri yapılarak her örneğin 3 kör pasajı gerçekleştirildi $[6,8,17]$.

\section{Bulgular ve Tartışma}

Gaita örneklerinde $\mathrm{BCoV}$ varlığının saptanması: İshalli buzağılardan toplanan 100 adet gaita örneklerinden 2 adetinde (\%2) RT-PCR ile BCoV varlığ pozitif olarak tespit edildi.

Human Rectal Tümör (HRT) hücre kültüründe $\mathrm{BCoV}$ izolasyonu: Gaita örneklerinden hazırlanan süpernatantlardan HRT hücre kültürlerine yapılan ekimlerde 3 kör pasaj sonrasında, $\mathrm{BCoV}$ izolasyonu yapılamadı [2,6], yapmış olduğu çalışmada, 116 erişkin sığırdan alınan gaita örneklerini $\mathrm{BCoV}$ antijenleri yönünden ELISA ile, 919 erişkin sığırdan alınan kan örneklerini Coronavirus spesifik antikorlar1 yönünden mikronötralizasyon testi ile incelen- 
diğini, elde edilen veriler sonucu erişkin sığırlarda Coronavirus enfeksiyonunun yaygın olduğunu ve yeni doğanların Coronavirus enfeksiyonlarında, erişkin sığırların da bir epidemiyolojik kaynak olarak değerlendirilmesi gerekliliğini ortaya koymuştur. Erdoğan ve ark.,(2003) Kars ve yöresinde neonatal buzağılarda BRV ve BCoV'unun yaygınlığının belirlenmesi amacıyla yaptıkları çalışmada, neonatal buzağılarda ishal insidensi \%28,8 olarak bulunurken BRV ve BCoV'ların prevalanslarını sırasıyla \%31,1 ve \%2,2 olarak belirlemişlerdir. Türkiye'nin 16 farklı ilinden toplanan 1-30 günlük ishalli buzağıya ait 185 gaita örneğinin 48 'inde $(\%$ 25,9) BRV, 27'sinde tek başına BRV, 24'ünde (\% 13) $\mathrm{BCoV}, 8$ 'inde tek başına $\mathrm{BCoV}$, 9'unda $\mathrm{BRV}+\mathrm{BCV}$ birlikte tespit edilmiştir [6]. İshal semptomu gösteren 83 buzağıdan sağlanan gaita örneklerinin 52'sinde $(\% 61,4) \mathrm{BRV}$ ve BCoV yönünden etkenlerin varlığının saptandığını, 52 olgunun 7'sinde $(\% 13,4)$ BRV ve BCoV ile mix enfeksiyonlar olduğunu, $37(\% 71,1)$ olguda sadece BRV ve $8(\% 15,4)$ olguda sadece $\mathrm{BCoV}$ etkenlerinin varlığının ELISA tekniği ile saptandığını bildirmiştir [2,20], tarafından 180 ishalli sı ğırdan sağlanan gaita ve nazal svap örneklerinin kontrolü sonucunda gaita örneklerinin \%3 ünde, nazal svap örneklerinin \%31'inde virus izolasyonu yapılmak suretiyle BCoV enfeksiyonunun varlığı saptanmıştır. Araştırıcılar ishalli buzağ1lar ile aynı ahırda bulunan sağlıklı görünümlü buzağıların nazal svap örneklerinin \% 25 inde $\mathrm{BCoV}$ varlığını bildirmişlerdir.

[1] yaptıkları çalışmada, ishal görülen 8 haftalık 108 buzağıdan topladıkları gaita örneklerinde ELISA metodu ile $\mathrm{BCoV}$ oranının \%38,9 olarak saptandığını bildirmişlerdir.

[17], tarafından Çin'de yapılan araştırmada buzağılarda ishallerin ilk 2 aylık dönem içinde olduğunu, morbidite oranın \%98,8 (78/79), mortalite oranının \%10 (8/79) olarak saptandığını, çalışmalarında 10 adet ishalli buzağılara ait gaita örneklerinin $\mathrm{BCoV}$ yönünden 10 örnekten HA-HI ile 4 $(\% 40)$ adetinde, ELISA metodu ile $6(\% 60)$ adetinde BCoV'un pozitif bulunduğunu bildirmişlerdir.

[22], Endonezya'da ishalli 78 buzağıya ait gaita örneklerinde $\mathrm{BCoV}$ oranını \%5 olarak saptamışlardir.

[9], tarafından 121 sı̆̆ır gaitasında $\mathrm{BCoV}$ antijenleri yönünden ELISA metodu ile yapılan tara- malarda, 121 gaita örneğinin 6'sında (\%5) serbest, 85 'inde $(\% 70)$ ise $\mathrm{BCoV}$ 'larının immunglobulinleri ile complex halde olduklarını tespit ettikleri bildirilmiştir.

[15], ishal görülen 8 buzağının gaitaları üzerinde yaptıkları çalışmada 1 buzağıda aynı hafta içinde gaita ve nasal svaplarında $\mathrm{BCoV}$ 'u tespit ettiklerini, bir buzağıda doğumdan sonraki 4. haftada önce gaitada sonra 6. haftada nasal svaplarında, bir buzağ1da ise 9. haftada gaita örneğinde, 10. haftada ise nasal svaplarında $\mathrm{BCoV}$ tespit ettiklerini bildirmişler, $\mathrm{BCoV}$ epidemiyolojisinde buzağı ishallerinde respiratorik formun, virus saçımı yönünden üzerinde durulmasının gerekliliğini vurgulamışlardır. Tarafimızdan yapılan bu çalışmada ishal görülen 100 buzağıya ait gaita örneklerinden 2'sinde \%2 oranında ELISA ve RT-PCR ile BCoV antijenleri tespit edilmiştir. Tespit edilen bu oran [10], tarafindan bildirilen orana yakın olmasına rağmen, ayn tespit oranının yapılan diğer bazı çalışmalarda bildirilen $[1,2,9,15,20,22]$ oranlardan çok düşük olduğu görülmüştür.

BCoV'unun meydana getirdiği enteritis vakaları buzağıların yaşına, immun sistemin durumuna, virus suşuna ve dozuna bağl1 olarak değişiklik gösterir. Özellikle kolostrum almamış genç buzağılarda şiddetli ishal ortaya çıkar. Buzağılarda enteritis vakalarında virus saçılımı enfeksiyonu izleyen günlerde azalacağından ishal görülen buzağılarda enfeksiyonun ilk 2 gününde gaita örneğinin alınması ve alınan örneklerin soğuk zincir altında dondurulmadan laboratuarlara gönderilmesi $\mathrm{BCoV}$ unun tespitinde önemlidir. Gaita örneklerinin $\mathrm{BCoV}$ yönünden uygun olmayan şartlarda muhafaza edilmesi ve buzağılarda belli bir tedavi süreci sonrası analiz için gaita örneklerinin laboratuvara gönderilmesi $\mathrm{BCoV}$ tespitini zorlaştırmaktadır.

Deneysel enfeksiyonlarda virus inokulasyonunu takiben 48 saat sonra sarı ishal belirtileri gelişir ve 3-6 gün sürer. Bu periyotta virus gaitada saptanabilir [21,22]. Ancak direkt gaita süpernatantı ile yapılan patojenite çalışmasında buză̆ılarda ishal ile karakterize klinik bulguların saptanamamas1nın, RT-PCR ile BCoV pozitif gaita örneklerindeki BCoV'nun inaktif olmasından kaynaklandığı düşünülmektedir. Bu sonuç bize, buzağılarda enteritis vakalarında $\mathrm{BCoV}$ unun tespitinde virus saçılımının enfeksiyonu izleyen günlerde azalacağından, ishal 
görülen buzağılarda enfeksiyonun ilk 2 gününde gaita örneğinin alınması ve alınan örneklerin soğuk zincir altında dondurulmadan laboratuarlara gönderilmesinin önemini ortaya koymaktadır.

Tarafımızdan yapılan bu çalışmada BCoV oranının düşük bulunması (\%2) ve virusun izole edilememesinin, gaita örneklerinin buzăğlarda ishale karşı bir tedavi uygulandıktan sonra alınmasından ve gönderilme esnasında soğuk zincire uyulmamasından kaynaklanabileceği, ayrıca [9], tarafından da bildirildiği üzere, gaita örneklerinde $\mathrm{BCoV}$ 'larının immunglobulinleri ile complex halde olduklarından, özellikle ELISA ile düşük oranda bulunduğu kanaatine varılmıştır.

\section{Kaynaklar}

1. Abraham, G., Roeder, P. L., and Zewdu R.., (1992). Agents associated with neonatal diarrhea in Ethiopian dairy calves. Tropical Animal Health \& Production 24,74-80.

2. Alkan, F., (2002). Siğırlarda Coronavirus Enfeksiyonunun Epidemiyolojisi. Ankara Üniversitesi Bilimsel Araştırma Projesi Kesin Raporu.

3. Benfield, D.A. and Saif, L. J., (1990). Cell culture propagation of a coronavirus isolated from cows diarrhea in Great Britain and Denmark, Vet Microbiol 3, 101-113.

4. Bridger, J.C., Woode, G. N., Meyling, A.,1978). Isolation of coronaviruses from neonatal calf diarrhea in Great Britain and Denmark. Vet Microbiol 3, 101-113

5. Chengping, L., Huochun, Y., Eichorn, W., (1991). Coronavirus as an agent of Neonatal calf diarrhea in a Chinese dairy cattle farm. J Vet Med B 38, 473-476.

6. Cho, K. O., M. Hasoksuz, P. R. Nielsen, K. O. Chang, S. Lathrop, and L. J. Saif., (2001). Cross-protection studies between respiratory and calf diarrhea and winter dysentery coronavirus strains in calves and RT-PCR and nested PCR for their detection. Archives of Virology 146, 2401-19.

7. Choenthaler S.L. and Kapil S.,(1999). Development and application of a bovine coronavirus antigen detection enzyme - linked Immunosorbent Assay. Clinic. and Diagnos. Lab. Immuno. Jan. 130-132.

8. Clark, M. A., (1993). Bovine coronavirus. British Veterinary Journal 149, 51-70.

9. Crouch C.F. and Acres S.D., (1984). Prevalence of rotavirus and coronavirus antijens in the feces of normal cows. Can.J.Comp.med., 48, 340-342.

10. Erdoğan H.M, Ünver Ahmet, Güneş Vehbi, Çitil Mehmet.,(2003). Frequency of Rotavirus and Coronavirus in Neonatal Calves in Kars District. Kafkas Univ. Vet Fak. Derg. 9(1): 65-68
11. Hasoksuz M, Hoet AE, Loerch SC, Wittum TE, Nielsen PR, Saif LJ., (2002). Detection of respiratory and enteric shedding of bovine coronaviruses in cattle in an Ohio feedlot. $\mathrm{J}$ Vet Diagn Invest.,14(4),308-13.

12. Hasoksuz M, Lathrop S, Al-dubaib MA, Lewis P, Saif L.J., (1999). Antigenic variation among bovine enteric coronaviruses (BECV) and bovine respiratory coronaviruses $(\mathrm{BRCV})$ detected using monoclonal antibodies.Arch Virol., 144(12),2441-7.

13. Hasoksuz M, Lathrop SL, Gadfield KL, Saif L.J.,(1999). Isolation of bovine respiratory coronaviruses from feedlot cattle and comparison of their biological and antigenic properties with bovine enteric coronaviruses. Am J Vet Res,. 60(10),1227-33.

14. Hasoksuz, M., Kayar, A., Dodurka, T., Ilgaz, A., (2005). Detection of respiratory and enteric shedding of bovine coronaviruses in cattle in Northwestern Turkey.Acta Vet Hung., 53(1),137-46.

15. Heckert, R. A., Saif, L. J., G. Myers, W., and Agnes., A. G., (1991). Epidemiologic factors and isotype-specific antibody responses in serum and mucosal secretions of dairy calves with bovine coronavirus respiratory tract and enteric tract infections. Am J Vet Res,. 52,845-51.

16. Heckert, R. A., Saif, L. J., Hoblet K.H. and Agres A.G., (1990). A longitudinal study of bovine coronovirus enteric and respiratory infection in dairy calves in two herds in Ohio. Vet. Microbiol., 22,187-201.

17. Lu. C., Yao H. and E1chhorn W., (1991). Coronavirus as an agent of neonatal calf diarrhea in a chinese dairy cattle farm. J.Vet. Med., 38,473-476.

18. Mebus, C. A., Stair, E. L. Rhodes, M. B., and Twiehaus, M. J., (1973). Neonatal calf diarrhea: propagation, attenuation, and characteristics of a coronavirus-like agent. Am J Vet Res,. 34,145-50.

19. Reynolds, D. J., Chasey, D. A., Scott, C., and Bridger, J. C., (1984). Evaluation of ELISA and electron microscopy for the detection of coronavirus and rotavirus in bovine faeces. Veterinary Record., 114, 397-401.

20. Tsunemitsu, H., Kanawati, Z. R., el- Smith, D. R., Reed, H. H., and Saif, L. J, (1995). Isolation of coronaviruses antigenically indistinguishable from bovine coronavirus from wild ruminants with diarrhea. Journal of Clinical Microbiology 33,3264-9.

21. Van Kruiningen, H. J., Castellano, V. P., Torres, A., and Sharpee, R. L.. (1991). Serologic evidence of coronavirus infection in New York and New England dairy cattle with winter dysentery. Journal of Veterinary Diagnostic Investigation., 3,293-6.

22. Waltner T.D., Martin S.W. and Meek A.H. (1986). An epidemiological study of selected calf pathogens on holstein dairy farms in southwestern ontario. Can J. Vet. Res. 50: 307-313. 